\title{
La cadena de valor de la panela y el fortalecimiento de la agricultura familiar en Costa Rica
}

\author{
The value chain of panela and the strengthening of family farming in Costa Rica
}

\author{
Jessica Arias Ramírez \\ Maestría en Desarrollo Sostenible, Universidad de Costa Rica, jearra17@hotmail.com \\ Jorge Andrey Valenciano Salazar \\ Universidad Nacional, Costa Rica y Facultad de Ciencias Económicas y Empresariales, \\ Universidad Complutense de Madrid, España, jorgvale@ucm.es
}

Fecha de recepción: 30/01/2017. Fechas de reenvíos: 22/03/2017- 28/03/2017, 30/03/2017- 18/06/2017, 8/08/2017-24/08/2017. Fecha de aprobación: 1/09/2017.

Fecha de publicación: 11/09/2017.

\begin{abstract}
Resumen: El artículo presenta una descripción general del funcionamiento de los agentes que componen los eslabones de la cadena de producción y comercialización de la panela (dulce producido del jugo de la caña de azúcar), con el objeto de determinar el efecto socioeconómico y ambiental de esta actividad sobre la zona geográfica donde operan los eslabones agrícola y agroindustrial. Se emplean el enfoque de cadenas globales de mercancías (CGM) y el de desarrollo sostenible, los cuales permiten establecer las interconexiones socioeconómicas entre los diferentes agentes y actores alrededor de un producto, así como los efectos ambientales sobre la zona de influencia. Este estudio logra determinar el efecto de los productores de caña y las industrias familiares procesadoras de panela (trapiches), ubicados en los primeros eslabones de la cadena como dinamizadores del desarrollo sostenible y la agricultura familiar en la comunidad de La Paz de San Ramón, Costa Rica.
\end{abstract}

Palabras clave: Agrocadenas; caña de azúcar; panela; agricultura familiar.

\begin{abstract}
This paper includes a general description of the agents comprising the stages in the production and commercialization chain of panela (unrefined whole cane sugar). The objective was to determine the socioeconomic and environmental impact of this activity in the geographical area where the agricultural and agro-industrial stages occur. The Global Commodity Chain (GCC) and sustainable development approaches were used, which allow to establish socioeconomic interconnections between the different agents and players related to a product, as well as the environmental effects on the influence area. This study determined the effect of sugar cane producers and family-owned sugar cane mills (trapiches), located in the first stages of the chain, as invigorating and driving forces of sustainable development and family farming in the town of La Paz, San Ramón, Costa Rica.
\end{abstract}

Keywords: agricultural chain; sugar cane; panela (raw cane sugar); family farming. 
Vol 37, N 55, (1-13), EISSN: 2215-2997, julio - diciembre, 2017

URL: www.revistas.una.ac.cr/abra

DOI: http://dx.doi.org/10.15359/abra.37-55.3

\section{Introducción}

Las cadenas de valor orientadas a los mercados locales pueden ser dinámicas e innovadoras, adaptándose tanto a las condiciones de mercado como a las presiones sobre el uso de los recursos. En este sentido, no solo las cadenas globales ligadas a mercados internacionales se vuelven objetos de estudio, sino también los sistemas de producción agrícolas y agroindustriales locales son interesantes de abordar y estudiar por las dinámicas productivas que se desarrollan alrededor de la producción de un bien, así como los encadenamientos a nivel local y las interconexiones culturales y comerciales entre los distintos actores que componen los eslabones de la cadena.

Si bien la modalidad de agricultura empresarial y a gran escala busca satisfacer una serie de demandas propias del sistema de consumo mundial actual, existe también una agricultura más local y rural basada en una producción a cargo generalmente del núcleo familiar, que por sus características de producción genera procesos más sostenibles y con mayor impacto sobre la calidad de vida de la población local. En este sentido, la producción de panela o tapa de dulce en la comunidad de La Paz, ubicada en el cantón de San Ramón, Costa Rica, involucra una serie de actores que van desde el eslabón agrícola, agroindustrial hasta el de comercialización, que conservan las características de ser productores a pequeña y mediana escala con una orientación de mercado meramente local.

La producción de caña de azúcar en el caso estudiado se realiza mediante una agricultura familiar, cuyo reciente auge y notoriedad radica en que se le está considerando como opción viable y factible para la implementación del desarrollo rural sostenible, así como una importante forma de producción y distribución que garantiza la seguridad alimentaria de los pueblos y la preservación de la cultura.

El presente estudio emplea el enfoque de cadena global mercancía -CGM- para analizar los principales factores y actores de la agrocadena familiar del dulce que inciden en el desarrollo rural sostenible de la comunidad La Paz, en San Ramón de Costa Rica. Esto, a la luz de las dimensiones de la sostenibilidad (ámbito social, económico, ambiental y político-institucional), propuestas por Sepúlveda, Rodríguez, Echeverri y Portilla (2003). El estudio se realiza con el fin de plantear alternativas que permitan mejorar la sostenibilidad de la cadena en el territorio, y contribuir así a las distintas estrategias de fortalecimiento local.

El artículo está organizado de la siguiente manera: en el presente apartado se realiza la introducción del tema y del caso, en el siguiente se realiza un resumen del marco conceptual utilizado como base de la investigación, seguidamente se presenta la metodología utilizada, por último, se presentan los principales resultados y conclusiones del análisis. 


\section{Producción de dulce o panela en Costa Rica}

Estudios como el de Soto, León y Arroyo (2010) señalan que la cantidad de entregadores/ productores de caña (tanto para azúcar como para dulce) va en descenso, parte importante de la tendencia a la baja en el número de productores se explica por la continua reducción en el cultivo de la caña en las regiones tradicionales del Valle Central occidental y la cuenca alta del Reventazón. Esto, debido a que las condiciones topográficas de esta zona limitan el proceso de mecanización, así como a la competencia por tierra ante otros cultivos como café y ganadería; dicha situación también obedece a la demanda de tierra para realizar otras actividades más rentables como la inmobiliaria.

Según datos de la Secretaria Ejecutiva de Planeación Sectorial Agropecuaria [SEPSA] (2012), para el 2011 el área sembrada de caña en Costa Rica era de 57.480 hectáreas. De ese total de hectáreas cultivadas de caña, aproximadamente 947 son dedicadas a la elaboración de dulce o panela (Flores, 2007). Por su parte, la producción de dulce pasó de 42 mil toneladas anuales en 1950 a 4.600 en la actualidad, mostrando una reducción de casi un 90\% (Soto, et.al, 2010), debido entre otros factores, a cambios en el mercado, estilo de vida y patrones de consumo.

Actualmente muy pocas zonas en el país se dedican a la producción de dulce, uno de los sitios con mayor presencia de trapiches dedicados a su producción es la zona de San Ramón, específicamente La Paz, lugar donde se realizó el presente estudio, debido a la importancia que tiene esta actividad en la generación de empleo, de encadenamientos productivos y comerciales; así como en el mantenimiento de una actividad que desde el proceso de cultivo, producción y consumo conserva acervos culturales y ambientales importantes a nivel regional y de país.

\section{Maro conceptual}

El presente artículo utiliza varios marcos teóricos que ayudan a explicar la influencia de los agentes que integran la agrocadena del dulce sobre el desarrollo sostenible de la región geográfica donde se realizan las actividades, las cuales generan valor agregado.

Para explicar estas conexiones entre la dinámica productiva y sus efectos en la esfera socioeconómica y ambiental del medio rural, se utilizan los enfoques de desarrollo sostenible, agricultura familiar y cadenas globales de mercancías (CGM). 


\section{El desarrollo sostenible}

La Organización de las Naciones Unidas (ONU) define el desarrollo sostenible como:

Aquel que satisface las necesidades de la generación presente sin comprometer la capacidad de las generaciones futuras para satisfacer sus propias necesidades, mediante un proceso de cambio en el que la explotación de los recursos, la orientación de la evolución tecnológica y la modificación de las instituciones están acordes y acrecientan el potencial actual y futuro para satisfacer las necesidades y aspiraciones humanas. (Organización de las Naciones Unidas [ONU], 1987, p.1).

Dentro del concepto de desarrollo sostenible existen distintas dimensiones; en el presente estudio se abordan cuatro, a saber: sociocultural, económico, ambiental y político-institucional (Sepúlveda et al., 2003).

Ahora bien, una de las aproximaciones del desarrollo sostenible es el desarrollo rural sostenible con enfoque territorial (DRSET) (Sepúlveda, 2008). Este tiene como característica la multidimensionalidad del desarrollo sostenible, ya que cuenta con el ámbito social, económico y ambiental. Los tres, a su vez, se ven regulados y orientados por una cuarta dimensión que corresponde a la política-institucional (Sepúlveda, 2008). Además, reconoce la importancia de los encadenamientos, donde prima el deseo de alcanzar objetivos múltiples y de articular procesos productivos a través de conglomerados, fortalecimiento de las cadenas agroalimentarias territoriales y la denominación de origen (Sepúlveda et al., 2003). Por lo tanto y de acuerdo con Samper, et al., (2006), un enfoque de esta naturaleza, con una visión holística que reconozca a la ruralidad como un sistema complejo constituye una necesidad en las actuales propuestas de desarrollo rural.

\section{Agricultura familiar (AF)}

La Organización de las Naciones Unidas para la Alimentación y la Agricultura (FAO) integra dentro de la agricultura familiar a:

...productores agrícolas, pecuarios, silvicultores, pescadores artesanales y acuicultores...que tienen acceso limitado a recursos de tierra y capital, que tiene un uso preponderante de fuerza de trabajo familiar y la actividad agropecuaria/ silvícola/acuícola/pesquera es su principal fuente de ingresos, que complementa con otras actividades no agrícolas realizadas dentro o fuera de la unidad familiar. (Organización de las Naciones Unidas para la Alimentación y la Agricultura [FAO], 2012, p. 4). 
Esta definición de AF es amplia e intenta establecer un concepto general de este tipo de agricultura a nivel mundial, sin embargo, existe una definición mucho más concreta planteada por el Comité Nacional de Agricultura Familiar de Costa Rica que la define en los siguientes términos:

Una forma de vida de familias rurales, urbanas y periurbanas, incluidas las campesinas, indígenas y pesqueras, que a partir de su actividad productiva generan alimentos y servicios que contribuyen con la seguridad y soberanía alimentaria y nutricional y con el buen vivir tanto de las familias como de la población. Constituye un continuum, desde los sistemas de autoconsumo hasta los sistemas de producción familiar con suficiencia de mercado y de recursos. La AF promueve el desarrollo asociativo, integral y sustentable y los principios del comercio justo. Sus bases culturales, sociales, ambientales y económicas se encuentran en su entorno familiar y territorial; incorpora, valora y respeta a todos los miembros de la familia desde las perspectivas de la inclusión y la multiculturalidad y promueve el arraigo y la identidad para la integración generacional. (Comité Nacional de Agricultura Familiar de Costa Rica, Ministerio de Agricultura y Ganadería [MAG], 2015, pp. 2-3).

La AF se caracteriza por ser un modo de vida con una importante influencia en los espacios rurales desde la parte ambiental, social, económica hasta lo cultural. Es también considerada, según el gobierno de Costa Rica, como la base de la producción sostenible de alimentos, contribuyendo así a la seguridad alimentaria a largo plazo, la preservación de la biodiversidad y la herencia cultural en las zonas rurales (MAG, 2012).

Por lo tanto, según aproximaciones de FAO (2012) y Schneider (2003), se considera la agricultura familiar como un modelo productivo que favorece el arraigo de la familia; crea redes de protección social; permite preservar y potenciar aspectos culturales, habilidades, destrezas y tradiciones; genera empleo directo e indirecto en la medida que sus actividades se orientan a los mercados e incorporan valor a los productos antes de su comercialización.

\section{Cadenas globales de mercancías/valor (CGM)}

La cadena de valor puede definirse como "la variedad total de actividades requeridas para conducir un producto desde su concepción hasta la entrega al consumidor, la disposición y el deshecho final a través de diversas fases intermedias de producción" (Kaplinsky y Morris, 2000, p. 4), concepto inmerso dentro del enfoque de la cadena global de mercancía (CGM).

Una CGM está conformada por un conjunto de redes organizadas entre sí, agrupadas alrededor de una mercancía o producto, que conecta entre sí, unidades familiares, empresas y Estados dentro de la economía mundial (Gereffi y Korzeniewicz, 1994). En el enfoque de CGM se presenta el concepto de la cadena agroproductiva desde un punto de vista positivo, describiendo y analizando los actores e interrelaciones existentes (Díaz y Hartwich, 2005). 
El estudio de la estructura y dinámica de las CGM implica considerar cuatro dimensiones básicas, las cuales, según Gereffi y Korzeniewicz, (1994); Diaz y Pelupessy (2004), y Pelupessy (2001) son:

- La dimensión del valor agregado (estructura insumo-producto): va desde la extracción de materia prima y el procesamiento hasta el consumo y la disposición final. Permite, en principio, la consideración, en el análisis, de los procesos técnicos y sus cambios, la organización industrial y la distribución de las rentas técnicas. En el caso de la cadena del dulce en La Paz, se analiza el proceso por el cual pasa la caña hasta llegar a convertirse en dulce, es decir, desde la producción de la caña de azúcar hasta su comercialización y consumo, considerando los diferentes eslabones, procesos técnicos, aspectos sociales y ambientales entre otros.

- La dimensión de la ubicación del espacio de las actividades productivas (dimensión geográfica): las actividades productivas pueden incluir cualquier país, región y localidad, incluidas sus diferencias socioculturales y geográficas.

- La dimensión de las políticas estatales y arreglos institucionales (contexto institucional y socio político): las estructuras y dinámicas de la CGM son afectadas por políticas estatales y arreglos institucionales (interna/externamente). Se considera para la cadena de dulce de La Paz el papel del Estado por medio de diferentes instituciones relacionadas con el cultivo de la caña y la producción de dulce en los trapiches.

- Fuerza motriz o estructura de control: se trata de una empresa o grupo de empresas que coordinadamente dominan la extensión, la naturaleza y el flujo de los recursos dentro de la cadena y actúan como fuerza motriz y estructura de control.

Dicha estructura de control, en el caso de la cadena del dulce, se determina con base en los resultados de la investigación al identificar cuál es el actor que tiene más dominio en el funcionamiento de la cadena, ya sean: productores, encargados/dueños de trapiches, comerciantes, consumidor o las instituciones vinculadas a la producción de dulce.

De esta forma, la AF es vista como un motor en las zonas rurales, donde puede propiciar el desarrollo sostenible, mientras que la cadena global de mercancías muestra el estado y funcionalidad de dicha agricultura para identificar sus puntos débiles y fuertes de manera sistemática y organizada. 


\section{Materiales y métodos}

\section{Área de estudio}

El estudio se realizó en La Paz, una comunidad de 1.400 habitantes aproximadamente que se encuentra en el distrito de Piedades Norte. Tiene una población de 8.148 habitantes, según datos del Censo de Población y Vivienda realizado por el Instituto Nacional de Estadística y Censos (INEC) en el año 2011. Ubicada al noreste de Costa Rica, a una altitud entre 1.100 y 1.3000 msnm, con un bosque tropical húmedo pre montano. Las principales actividades agrícolas en la zona son: caña de azúcar, café, hortalizas, ganadería (de muy pequeña escala).

Es una zona de riqueza cultural donde se realizan actividades de importancia nacional como el Desfile de Bueyes, realizado desde hace 50 años para las fiestas patronales, en el cual las carretas desfilan con caña, producto que ha favorecido la existencia de los trapiches en la zona. En esta línea, Castro (2007-2008), se refiere a La Paz como un sitio de visitación y de actividades atractivas, con su concentración de trapiches con diversas tecnologías.

En este sentido, la producción de dulce mantiene relaciones de impulso no solo a nivel económico (empleo, valor agregado), sino también social y ambiental; conserva prácticas culturales de producción a nivel de pequeña propiedad y de consumo de un bien que ha ido perdiendo su preferencia entre las nuevas generaciones, frente a otras opciones de bebidas como el café, el té o las gaseosas; sin embargo, recientemente se vislumbran nuevas opciones para el dulce ante el surgimiento de mercados diferenciados y específicos.

\section{Población y muestra de estudio}

La población de estudio correspondió a los actores principales dentro de la cadena de valor de la panela en la comunidad de La Paz, identificados como:

- Los productores: son quienes cultivan y cosechan la caña destinada a la producción de dulce, son 45 pequeños productores que destinan su caña de azúcar para la producción de dulce o panela, se entrevistaron 43, una muestra representativa para los productores agrícolas a un nivel de confianza del $97.5 \%$ con un margen de error del $5 \%$ y un nivel de heterogeneidad de las unidades muestrales del $50 \%$.

- Los trapicheros (personal encargado de los trapiches, dueños o administradoras del trapiche): se entrevistó a cinco de los seis trapiches de la comunidad, por razones de conveniencia. Se garantizó una muestra representativa a un nivel de confianza del 95\% con un margen de error del 5\%, considerando homogeneidad en la población de trapiches. 
- Los comerciantes o intermediarios: son quienes compran el dulce a los trapiches, de ellos se obtuvo parte de información sobre el consumo final. Se aplicó la entrevista a tres comerciantes locales y a dos cadenas grandes de comercialización, se estima un total de 19, entre supermercados (nueve) y comerciantes independientes (diez).

- Los consumidores: son los compradores de dulce para su consumo final. Se obtuvo una muestra de 27 personas consumidoras con una selección a través del muestreo no aleatorio por conveniencia, de la zona occidental del Valle Central de Costa Rica, área de distribución principal del dulce producido en La Paz.

En el caso de los eslabones de comercialización y consumo de la cadena, se obtuvo y entrevistó una muestra no representativa estadísticamente tanto de comerciantes como de consumidores. La no representatividad estadística en estos casos responde a las siguientes razones:

a. Escasez de recursos económicos en el momento de realizar el trabajo de campo,

b. La investigación buscaba resaltar las interacciones de los primeros dos eslabones de la cadena con el medio rural.

c. La ausencia de una población conocida de consumidores de dulce en la región occidental del Valle Central de Costa Rica.

Además de las entrevistas a los actores que componen los eslabones de la cadena, se realizaron entrevistas a personal de algunas instituciones públicas vinculadas con la actividad del dulce en La Paz. El objetivo de las entrevistas fue completar y triangular la información expresada por los actores. Se incorporaron en el estudio las siguientes instituciones: el Ministerio de Salud (MS), el Ministerio de Ambiente y Energía (MINAE), La Cooperativa Cañera de San Ramón R.L (Coopecañera R.L.), el Ministerio de Agricultura (MAG), la Coordinadora Latinoamericana y del Caribe de Pequeños Productores y Trabajadores de Comercio Justo.

\section{Técnicas de investigación}

Se realizó una investigación no experimental de diseño transversal, siguiendo las dimensiones de la sostenibilidad propuestas en el referente teórico DRSET mediante el proceso metodológico de la CGM antes descrita. El proceso se describe a continuación:

1. Se realizaron visitas de campo en la zona para familiarizarse con el territorio, y los diferentes actores.

2. Se elaboraron los instrumentos de colecta de información para cada actor, diseñados con una serie de atributos y variables específicas, dependiendo del actor y su función dentro de la cadena (ver Anexo 1,2, 3 y 4) y se validaron en la zona. 
3. Se visitaron los trapiches y se colectaron datos, previa obtención del consentimiento informado de los participantes, se aplicaron las entrevistas estructuradas a los trapicheros. Se entrevistó además a los productores de caña y se realizaron visitas de campo a algunas de sus fincas para realizar una observación directa en los campos de cultivo (ver anexos 1 y 2 para detalle de las variables de la entrevista).

4. A los comerciantes o compradores principales del dulce de la zona, así como al público consumidor final de dulce, se les realizó una entrevista estructurada para completar así la cadena del producto (ver anexo 3 y 4).

5. Finalmente, toda la información se triangula con una entrevista semiestructurada a distintas instituciones previamente mencionadas.

Por lo tanto, se colectó información de toda la cadena del dulce. Según la naturaleza de la información requerida, asíseabordaron los diferenteselementoscon losactorescorrespondientes (ver tabla 1), posteriormente se agruparon según las dimensiones del desarrollo sostenible (ambiental, social, económico e institucional) para su posterior análisis por dimensión.

Tabla 1

Abordaje metodológico de la investigación

\begin{tabular}{|c|c|c|c|c|c|}
\hline \multirow{2}{*}{$\begin{array}{l}\text { Dimensiones según } \\
\text { la CGM }\end{array}$} & \multirow[t]{2}{*}{ Aspectos a analizar } & \multicolumn{4}{|c|}{ Actores involucrados en cada aspecto } \\
\hline & & Productor & Trapiche & Comerciante & Consumidor \\
\hline \multirow{6}{*}{$\begin{array}{l}\text { I- Insumo-producto } \\
\text { (Valor agregado-VA) }\end{array}$} & Materias primas & $\sqrt{ }$ & & & \\
\hline & Producción & $\sqrt{ }$ & & & \\
\hline & Procesamiento & & $\sqrt{ }$ & & \\
\hline & Comercialización & $\sqrt{ }$ & $\sqrt{ }$ & $\sqrt{ }$ & \\
\hline & $\begin{array}{l}\text { Consumo final y distribución } \\
\text { del valor agregado entre los } \\
\text { eslabones }\end{array}$ & & & $\sqrt{ }$ & \\
\hline & & & & & $\sqrt{ }$ \\
\hline \multirow{2}{*}{$\begin{array}{l}\text { Il-Geográfica } \\
\text { (ubicación) }\end{array}$} & Caracterización de territorio & $\sqrt{ }$ & & & \\
\hline & $\begin{array}{l}\text { Ventajas comparativas que } \\
\text { permiten la producción de } \\
\text { caña de la zona }\end{array}$ & $\sqrt{ }$ & $\sqrt{ }$ & & \\
\hline \multirow{2}{*}{$\begin{array}{l}\text { III- Fuerza motriz } \\
\text { (estructura de } \\
\text { control) }\end{array}$} & $\begin{array}{l}\text { Actores involucrados en la } \\
\text { cadena }\end{array}$ & $\sqrt{ }$ & $\sqrt{ }$ & $\sqrt{ }$ & \\
\hline & $\begin{array}{l}\text { Influencia de actores en la } \\
\text { cadena }\end{array}$ & $\sqrt{ }$ & $\sqrt{ }$ & $\sqrt{ }$ & \\
\hline \multirow[t]{3}{*}{$\begin{array}{l}\text { IV- Institucionales } \\
\text { (políticas estatales) }\end{array}$} & $\begin{array}{l}\text { Políticas } \\
\text { vinculantes }\end{array}$ & $\sqrt{ }$ & $\sqrt{ }$ & $\sqrt{ }$ & \\
\hline & Regulaciones & $\sqrt{ }$ & $\sqrt{ }$ & $\sqrt{ }$ & \\
\hline & Instituciones presentes & $\sqrt{ }$ & $\sqrt{ }$ & $\sqrt{ }$ & \\
\hline
\end{tabular}

Fuente: Elaboración propia, San Ramón, 2015. 


\section{Resultados}

\section{Generalidades de la cadena y producción del dulce en La Paz}

6. La cadena del dulce producido en La Paz, inicia con (i) el eslabón de materia primas, compuesto por las casas comerciales proveedoras así como las instituciones de apoyo y regulación de la actividad, luego (ii) los productores, que se encargan de cultivar, producir y cortar la caña, (iii) los trapicheros, pequeñas agro industrias donde se procesa el jugo de la caña de azúcar hasta convertirla en dulce, (iv) los intermediarios/comerciantes, encargados de la distribución y comercialización del dulce en la región y, por último, (v) el consumidor final, que compra el producto al eslabón anterior y lo consume (ver figura 1).

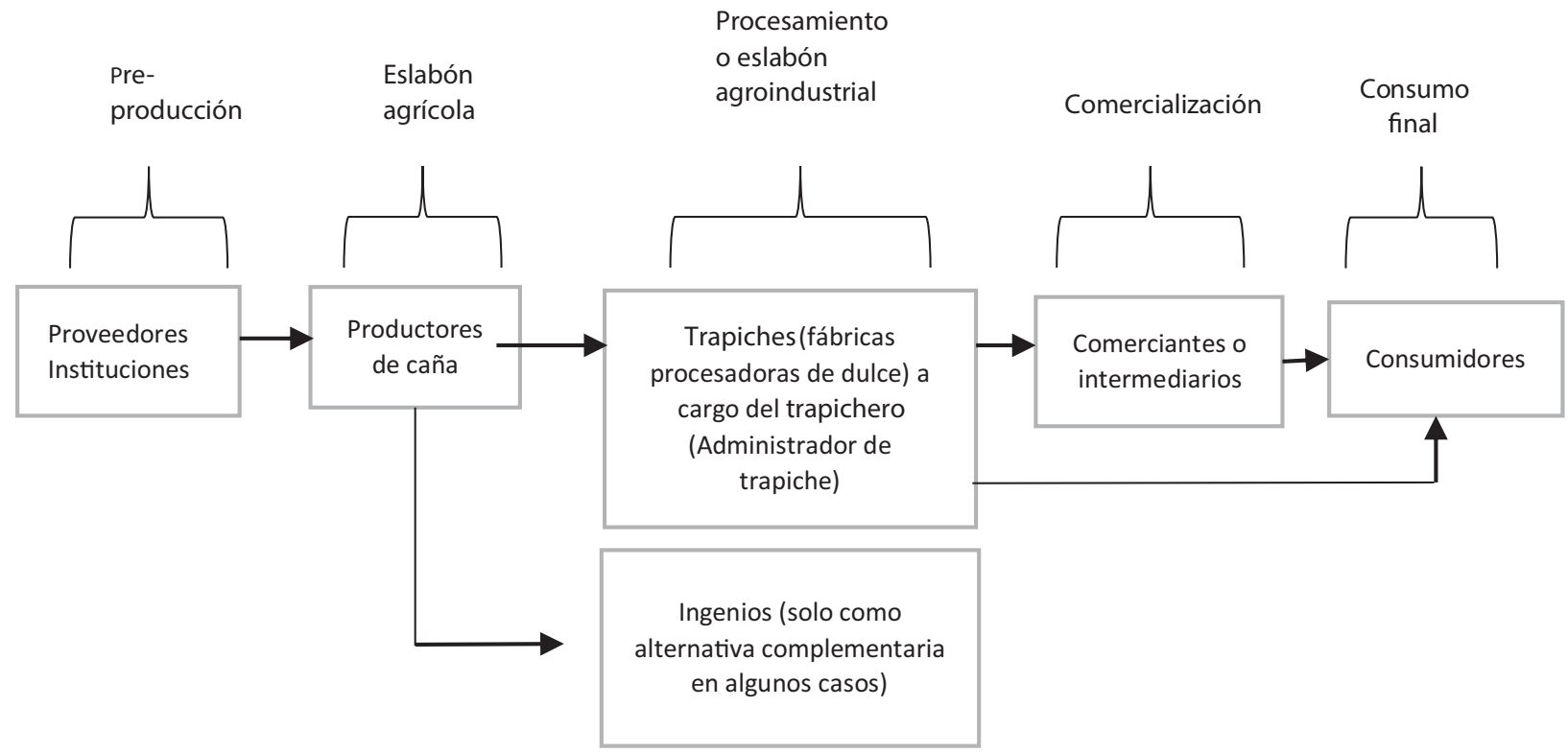

Figura 1. Flujograma general de la cadena del dulce en La Paz, San Ramón. Elaboración propia con base en recolección de datos en el 2014-2015, La Paz, San Ramón.

A continuación, se especifican las características principales de los actores que componen cada uno de los eslabones: 


\section{Eslabón de materias primas/preproducción}

Incluye los actores encargados de proveer las materias primas y la logística necesaria para la producción de la caña, como: el abastecimiento de las distintas variedades de semilla de caña, el agua y los insumos (fertilizantes y herbicidas, tanto orgánicos como sintéticos). Las casas comercializadoras de insumos se encuentran ubicadas en la ciudad de San Ramón de Alajuela. Algunas instituciones públicas como el Ministerio de Agricultura y algunas cooperativas de la zona como Coopecañera y CoopeVictoria, ayudan con capacitaciones a los productores y también con insumos como nuevas variedades de semilla de caña.

\section{Producción de caña}

Incluye procesos que van desde la preparación del terreno hasta la cosecha de la caña de azúcar (preparación, siembra, fertilización, limpia, aporca y corta, respectivamente). Estas prácticas se realizan tanto en forma mecánicas como manual. Los actores involucrados directamente son los productores y las instituciones que regulan en materia productiva y ambiental como el MINAE y MAG, así como las dedicadas a la capacitación como las universidades y los distintos institutos nacionales.

Las fincas incluidas en el estudio tienen en promedio extensiones de 5.1 hectáreas y en su mayoría (62.7\%) son terrenos con poca inclinación, además, el $51 \%$ tiene algún grado de cobertura boscosa, pero que en ningún caso dicha cobertura superó las 2 hectáreas por finca. Un 63\% de las fincas cuenta con alguna fuente natural de agua mayoritariamente quebradas seguido por nacientes, ríos y pozos.

En cuanto a las variedades de caña utilizadas en la región, los productores identifican un total de 15; sin embargo, cada productor en promedio solo emplea tres variedades distintas en su finca. Existe cierto grado de autonomía productiva, ya que el $68.7 \%$ de los agricultores, obtienen la semilla de sus propios cañales, $21.5 \%$ de otros productores de la zona y solo un $9.8 \%$ la compra a ingenios o cooperativas.

\section{Procesamiento de la caña y producción de la panela o tapa de dulce}

El procesamiento se lleva a cabo en los trapiches donde se va transformando la caña hasta convertirla en panela o dulce y sus distintas presentaciones.

En cuanto al tipo de propiedad, tres de los trapiches están conformados por sociedad anónimas privadas, otro es una asociación y otro tiene un único dueño. Los dueños o administradores, por su parte, tienen entre 40 y 61 años de edad, con experiencia en la actividad agrícola. 
Los trapiches en La Pazoperan con diferentes grados de tecnificación, uno es un trapicheeléctrico tradicional, la mayoría del proceso se realiza de forma manual y la fuente principal de energía es la electricidad, en este tipo de trapiche se usan aún las tradicionales pailas para almacenar y calentar el jugo de caña; hay tres trapiches con tecnología de calderas en los cuales el proceso es más tecnificado y complejo, emplean vapor de agua como principal recurso energético y el jugo es calentado en evaporadores, esto genera buenos rendimientos y capacidad productiva a los trapiches, y un único trapiche denominado caldera ecológica, el cual cumple los mismo principios de caldera, pero con mayores cuidados en la parte ambiental y detalles tecnológicos que lo hacen más eficiente Por lo tanto, la capacidad de producción de dulce y sus derivados varía de un trapiche a otro, dependiendo de la tecnología.

En general el procesamiento en el trapiche consiste en recepción y pesaje de la caña, la extracción de jugos o molienda, tratamiento y clarificación del jugo, para este último se emplean plantas como: guácimo (guazuma ulmifolia), burío (heliocarpus appendiculatus) o mozote (triumfetta spp.), seguidamente la concentración y evaporación del jugo, moldeo del dulce y finalmente el empaque y almacenamiento, y su posterior comercialización.

Los tiempos de producción son variables, dependiendo de la tecnología procesan 7 toneladas diarias en el caso del eléctrico tradicional y 25 en la caldera ecológica. En conjunto los trapiches de la zona procesan mensualmente alrededor de 300 toneladas de caña, operan en promedio tres días semanalmente y la mano de obra es, en su mayoría, familiar y de personal asociado.

Los trapiches en la Paz producen distintos productos, ligados a la demanda del mercado, los principales son: tapa de dulce o panela, atado, dulce granulado y perica o sobado (ver figura 2), hay otros en menor escala de producción que también aportan valor agregado (VA) como miel, caldo, cajetas y melcochas. Se generan también subproductos y residuos, los cuales, en su mayoría, se comercializan para uso en abonos orgánicos o alimentación de ganado, con lo cual se genera mayor valor agregado (VA) dentro de la agrocadena. Es posible utilizar estos residuos en las mismas fincas ya sea para alimentación de bovinos o para la elaboración de abono orgánico. 


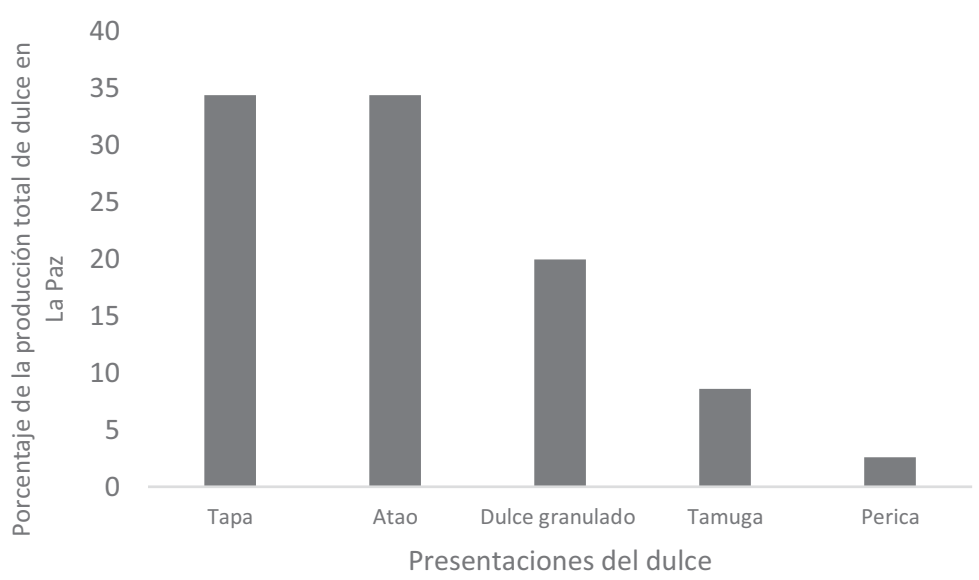

Figura 2. Porcentaje dentro de la producción total de dulce de la Paz, de las diferentes presentaciones de dulce, San Ramón. Recolección de datos en el 2014-2015, La Paz, San Ramón.

\section{Comercialización}

La cadena tiene dos flujos principales de comercialización y en momentos distintos, la comercialización de la caña hacia los trapiches y la comercialización del dulce en el mercado final.

La comercialización de la caña va a depender de la capacidad de recepción y procesamiento de los trapiches, así como de la demanda de dulce en el mercado, la cual tiene la característica de no ser constante a lo largo del año. Generalmente, cada trapiche realiza pedidos a los agricultores sobre la cantidad de caña semanal que van a requerir, y estos se encargan de proveerla.

El mercado del dulce de La Paz, tiene un carácter regional, con pocas excepciones, normalmente el dulce es distribuido en pulperías y supermercados de la región por los comerciantes o intermediarios que llegan a comprarlo directamente al trapiche (la mayoría de los comerciantes son de La Paz. Para estos actores de la cadena, la actividad de venta del dulce representa alrededor del $70 \%$ de sus ingresos mensuales.

La venta del dulce se realiza contra pedido, con el fin de no tener excedentes que no puedan comercializar. La demanda del producto es variable durante el año, se identificó que de octubre a marzo hay un aumento en la demanda del dulce, mientras que de marzo a agosto hay una considerable disminución. Además, los trapicheros detectaron un incremento en la demanda principalmente a finales de diciembre e inicios de enero, dentro de los factores que influyen en dicho incremento se tienen: el ingreso a clases y la época de recolección de café en la región. 
Mientras que la disminución se alude a épocas de cosechas de diferentes frutas y productos que llenan los mercados y cambian las prioridades de consumo.

Una deficiencia identificada es que no hay una búsqueda adecuada por parte de los actores de nuevos mercados (hay carencia de conocimientos de cómo hacerlo), los trapiches no tienen un buen mercadeo del producto, lo que afecta el resto de eslabones y actores en la cadena, en especial a los productores.

\section{Consumo final}

En cuanto a los consumidores entrevistados, se evidenció que el consumo de dulce se mantiene sobre todo en las personas de mayor edad y se establece una relación inversa entre edad y nivel educativo, de manera que a mayor escolaridad menor consumo de panela. Este comportamiento se debe a que las personas lo suelen sustituir por otras bebidas como café, té o gaseosas, y esto se relaciona a su vez, con que las personas de mayor escolaridad son jóvenes.

De las entrevista se destaca que un $78 \%$ de los consumidores consumen más dulce en Semana Santa, mientas que el $22 \%$ restante dijo mantener su consumo a lo largo del año. Las presentaciones más demandadas son el dulce granulado y la tapa para la elaboración de aguadulce y miel.

En este eslabón de la cadena, interesa explorar la posibilidad de nuevos productos y mercados, y se les consulta a los consumidores sobre su disposición a pagar entre un 5 y $10 \%$ más, por un dulce con certificación orgánico y 24 de los entrevistados indicaron que estarían de acuerdo. Esta posibilidad crea condiciones iniciales para mercados emergentes a nivel nacional e internacional al ofrecer productos diferenciados, con características que los hacen únicos (como la producción ecológica o las prácticas culturales), así como características de calidad y sabor de la panela. Por lo tanto, la cadena del dulce es una fuente potencial de exclusividad que los puede posicionar en nuevos mercados con consumidores que demandan productos de alta calidad y que protegen el ambiente.

\section{Resultados orientados a las dimensiones de la sostenibilidad}

\section{Dimensión económica de la cadena de dulce}

La agrocadena del dulce en La Paz de San Ramón genera 131 empleos directos en la comunidad. Solo en el eslabón agroindustrial compuesto por los trapiches, en días de operación requieren alrededor de 48 personas, 11 de esos puestos son ejercidos por mujeres. 
La generación de empleo dentro de la agrocadena influye en la economía local, ya que más del $60 \%$ de los ingresos de los núcleos familiares entrevistados, provienen de las actividades relacionadas con la producción de caña y de dulce, en promedio los productores obtienen semanalmente 40 mil colones de ingresos por la caña de azúcar. Este ingreso depende de la cantidad de caña que entregan a los trapiches (67.5\% de productores tienen dificultades en entregar toda la caña que está en su punto de maduración para ser procesada, por su dependencia de la demanda del dulce en el mercado). Esta falta de mercado ha llevado a la diversificación de la producción en la finca, principalmente con hortalizas, café y ganadería.

Para el $44 \%$ de los productores, la falta de capital para invertir, limita el tipo de producción que realizan y eso incluye la contratación de mano de obra adicional, ya que el costo aproximado mensual de un peón (jornalero) es de 160000 mil colones. Los pequeños productores hacen todo el proceso con mano de obra familiar, y de esa manera reducen los gastos en mano de obra, para hacer rentable la actividad.

El eslabón con mayor poder en la cadena es el procesamiento (estructura de control, en este caso), ya que los productores de caña, dependen totalmente de los trapiches para poder entregar su caña en los tiempos apropiados; de lo contrario, los agricultores deben vender su caña a los ingenios a un menor precio.

\section{Dimensión social/cultural de la agrocadena de dulce}

Los productores de caña de azúcar en la Paz de San Ramón se caracterizan por ser propietarios de pocas hectáreas de terreno (5.1 hectáreas en promedio); en consecuencia, el minifundio en propiedad privada es la característica principal de la tenencia de tierra, ya que solamente un $4 \%$ alquila terreno para cultivo.

Otra de las características principales de los agricultores de caña en La Paz de San Ramón, es su edad, tienen en promedio 59 años, este aspecto refleja que el relevo generacional dentro de la fase agrícola, no se está dando. Esta situación coincide con otras cadenas estudiadas como la del café en la zona de Turrialba, en donde la moda de edad de los caficultores de la zona supera los 45 años (Cordero \& Valenciano-Salazar, 2015, p. 9). Por otra parte, la longevidad de los productores reafirma que la siembra de la caña y la producción de dulce es una practica productiva y cultural dentro de la región occidental del Valle Central de Costa Rica y, además, identifica la gran expericia con que cuentan los productores de la zona , 47.7 años en el caso de agricultores y 42 años de experiencia en promedio en el caso de trapicheros.

Otro eslabón importante en el ámbito social y cultural son los consumidores, al consultar sobre las principales razones por las cuales consumen panela, expresaron motivos sociales, ambientales y económicos, entre ellos y ordenados por importancia están: (i) 85\% para mantener 
el dinamismo de la economía local, (ii) 85\% prefieren el dulce producido específicamente en La Paz de San Ramón por su calidad y precio, (iii) solo un $15 \%$ expresó que el precio era un factor importante.

\section{Dimensión ambiental de la cadena de dulce}

El área productiva de caña de azúcar en La Paz está en su mayoría rodeada por bosques, y parches de vegetación dentro de las fincas, es una zona de amortiguamiento ligada a la Reserva Biológica Alberto Manuel Brenes, sin embargo, los parches boscosos dentro de las fincas, no superan las dos hectáreas.

Las variaciones climáticas de los últimos años han impactado y generado inconvenientes a productores. La afectación sobre el cultivo de la caña incluye: maduraciones más rápidas (lo que afecta el ciclo de procesamiento de caña tradicional) o bien escasez de agua para el cultivo, lo que se traduce en dificultades económicas, no en gran escala, pero sí alterando la rotación de cultivo anual que tiene normalmente y que es muy particular a la zona.

Para la preparación de los suelos, el $62.8 \%$ de productores usa bueyes, $30.3 \%$ chapulín, y $6.9 \%$ manual. El uso de prácticas manuales y mecánicas para la remoción de maleza es muy empleado y parece que va en aumento, no se practica la quema mediante fuego de suelos o malezas, no obstante, usan herbicidas para su eliminación (12 tipos de productos químicos), además de fertilizantes químicos, todos estos generan residuos y desechos plásticos con destinos finales diversos (ver tabla 2).

Tabla 2

Destino de los desechos plásticos de aplicación de fertilizantes y herbicidas, según las prácticas de los productores de caña de La Paz, San Ramón.

\begin{tabular}{lrr} 
Destino de desechos plásticos & \multicolumn{2}{c}{ Cantidad de productores } \\
\cline { 2 - 3 } Basura municipal & 13 & Valor relativo \\
\cline { 2 - 3 } Cooperativa-ingenio-(reciclaje) & 11 & $35.1 \%$ \\
Guardarlos & 7 & $29.7 \%$ \\
Enterrarlos & 4 & $19.0 \%$ \\
Quemarlos & 2 & $10.8 \%$ \\
\end{tabular}

* Datos con base en los 37 productores que respondieron a la pregunta correspondiente a esta información Fuente: elaboración propia, con datos de entrevistas a productores, San Ramón, 2015. 
Las fincas con la diversificación productiva contribuyen a evitar la erosión de los suelos, además, la presencia de parches de bosque y cercas vivas, en conjunto con la conciencia ambiental de los actores de la cadena, favorecen la conservación de la biodiversidad de la zona.

El uso de productos orgánicos impacta positivamente no solo a nivel económico sino también ambiental, un $65 \%$ de los productores utilizan insumos orgánicos ( $13 \%$ de ellos son productores orgánicos) (ver figura 3). El uso de productos orgánicos y la producción orgánica de caña, se constituye en la en un reforzamiento para la creación de nuevos mercados con productos diferenciados (recuérdese que el $62 \%$ de los consumidores dijo estar dispuesto a pagar más por dulce certificado). Además $5 \%$ usan controles biológicos en sus plantaciones para el manejo de plagas, específicamente ratas.

El uso del agua en todo el proceso es fundamental para la producción de panela, los trapicheros califican como buena la calidad y excelente la cantidad del agua. Hay que tomar en cuenta que cuatro de los trapiches obtienen el agua para algunas de sus operaciones de ríos, tres de nacientes y dos de agua potable suministrada por Acueductos y Alcantarillados (AyA). En el aspecto ambiental, también se debe destacar que el 100\% del material de combustión usado en los trapiches es el bagazo, un subproducto que proviene de la caña molida.

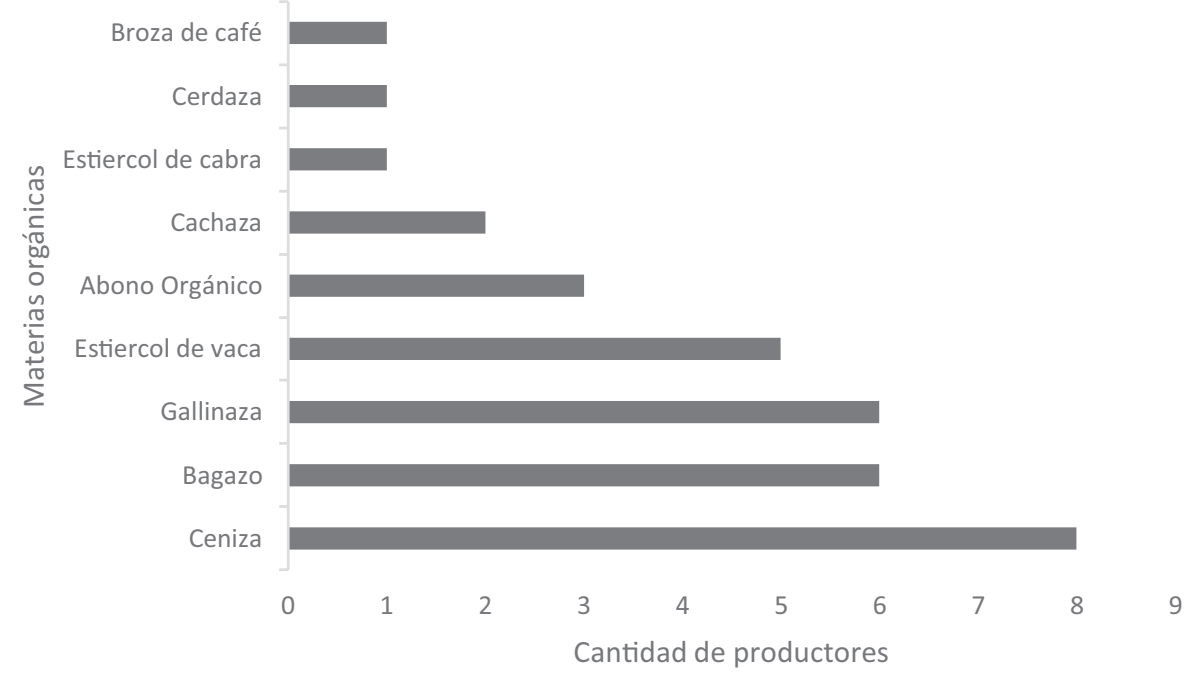

Figura 3. Materias o productos orgánicos empleados en los cañales por los productores de La Paz, San Ramón. Recolección de datos en el 2014-2015, La Paz, San Ramón. 
En cuanto a los desechos o subproductos que se generan en el eslabón agroindustrial así como las acciones para su manejo y uso se tienen las siguientes prácticas:

- Desechos/subproductos líquidos: plantas de tratamiento, sistemas de drenajes para aguas de lavado, almacenaje en tanques y posterior bombeo para riego en los mismos cañales.

- Desechos/subproductos sólidos: el bagazo se usa como abono para los cañales, alimento para el ganado y combustible para la hornilla o caldera del trapiche. Las denominadas cachazas (sólidos en suspensión que se retiran del jugo de la caña cuando estos se hierven) se emplean como herbicida natural en cañales y regulador de $\mathrm{PH}$, alimento para animales (ganado, cerdos, y gallinas), elaboración de abono orgánico e insumo en biodigestores.

- Desechos/subproductos gaseosos: del humo que es liberado al ambiente, se colecta la ceniza suspendida en el mismo para hacer abono orgánico.

El uso de los subproductos y desechos de la caña dentro de la misma cadena evita que estos terminen en fuentes de agua o afecten la salud de las personas. Sin embargo, su manejo final se podría mejorar considerablemente.

Por último, se consultó a los productores y trapicheros por prácticas que realizan en su finca o trapiche, que consideran importantes de conservar la calidad del ambiente para las futuras generaciones, estas se presentan en la tabla. 
Tabla 3

Prácticas y actividades que los productores y trapicheros consideran importante conservar

\begin{tabular}{|c|c|}
\hline \multicolumn{2}{|c|}{ Prácticas y actividades importantes de conservar } \\
\hline Productores (en fincas) & Trapicheros (en trapiches) \\
\hline $\begin{array}{l}\text {-No usar químicos (o lo menos posible) y usar } \\
\text { más el machete, cuchillo y la motoguadaña. } \\
\text {-Usar abono y productos orgánicos. }\end{array}$ & $\begin{array}{l}\text {-Uso de moldes de madera (pochote). } \\
\text {-Uso de guácimo, burío o mozote como } \\
\text { clarificantes. }\end{array}$ \\
\hline $\begin{array}{l}\text {-Protección de agua y nacientes } \\
\text {-Protección de los suelos. }\end{array}$ & $\begin{array}{l}\text {-Mantener los mismos procesos } \\
\text { productivos, pero mejores tecnologías. }\end{array}$ \\
\hline $\begin{array}{l}\text {-Conservación de áreas boscosas (en especial a } \\
\text { orillas de fuentes de agua). }\end{array}$ & $\begin{array}{l}\text {-Búsqueda y aplicación de tecnologías } \\
\text { amiaables con el ambiente. }\end{array}$ \\
\hline $\begin{array}{l}\text {-Recolectar y reciclar envases de químicos. No } \\
\text { enterrarlos, botarlos o quemarlos. }\end{array}$ & $\begin{array}{l}\text {-Consumo medicinal de "Las espumas" } \\
\text { (subproducto del proceso). }\end{array}$ \\
\hline -Conservación de las semillas. & \\
\hline $\begin{array}{l}\text {-Usar buenas (nuevas) variedades de caña. } \\
\text {-No practicar la quema. }\end{array}$ & $\begin{array}{l}\text {-Uso de la canoa para batir, ya que da } \\
\text { más calidad y sabor. }\end{array}$ \\
\hline $\begin{array}{l}\text {-Usar cercas vivas y rompe vientos naturales. } \\
\text {-Uso de controles biológicos. }\end{array}$ & $\begin{array}{l}\text {-Conservar el trapiche como un legado } \\
\text { cultural. }\end{array}$ \\
\hline -Realizar análisis de suelos. & \\
\hline -Renovación de cultivos. & \\
\hline$-U s c$ & \\
\hline
\end{tabular}

Fuente: Elaboración propia con datos de entrevistas a actores, San Ramón, 2015.

\section{Dimensión político-institucional de la cadena de dulce}

La dimensión político-institucional se abordó desde la percepción de los productores, trapicheros y comerciantes locales. Se consideraron dos categorías, a saber: (i) regulaciones e (ii) instituciones presentes de apoyo a la actividad.

Las regulaciones en la cadena incluyen normativas, legislaciones o cualquier tipo de regulación oficial, que los actores pudieran asociar con incidencia de una u otra forma a su actividad. En esta línea, un $69.7 \%$ de productores agrícolas de caña, desconocen del tema. Mientras que, de quienes dijeron saber de la existencia de alguna normativa/legislación, solamente el 31\% pudo especificar algún tipo de normativa, explícitamente mencionaron: "no usar químicos 28 días antes de entregar la caña", "los riegos de químicos son delicados", "tener cuidado con las 
Vol 37, N 55, (1-13), EISSN: 2215-2997, julio - diciembre, 2017

URL: www.revistas.una.ac.cr/abra DOI: http://dx.doi.org/10.15359/abra.37-55.3

quemas", "ambiente sano y no uso de herbicidas", "cuidado con la gallinaza por las moscas", "solicitar permisos a MINAE para quemas", "regulación de La Liga de la Caña", "regulación del Ministerio de Salud", "regulación de Liga Agrícola Industrial de la Caña de Azúcar (LAICA)".

De los 43 productores, únicamente dos manifestaron haber tenido en algún momento alguna dificultad legal al realizar la actividad cañera en relación cona alguna afectación ambiental dentro de su finca.

En el caso de los trapicheros, todos asegún reconocer la normativa y legislación vinculante a su actividad y mencionaron ideas más concretas ligadas a las regulaciones por ejemplo:"Ministerio de Salud", "Ley de Salud General", "Ministerio del Trabajo", "Instituto Nacional de Seguros (INS)", "Salud ocupacional y manufactura","Reglamento de Calderas","Leyes de producción alimenticia", "Patentes municipales", "Ministerio de Hacienda (tributación)". Tres trapicheros manifestaron haber tenido dificultades con la legislación/normativa vinculante a su actividad.

Se debe agregar además que la forma de participación de las instituciones puede ser muy variable, desde ente regulador hasta fuente de apoyo, capacitación, asesoría o financiamiento a los actores de la cadena. En cuanto a la presencia institucional en la cadena en general, un total de 14 instituciones fueron mencionadas por los distintos actores.

Las instituciones y su incidencia en la cadena varían dependiendo del actor y su percepción, en el caso de los comercializadores solo reconocieron al Ministerio de Salud (MS), (aborda aspectos de salud pública en la cadena) y el MAG. Por su parte, los agricultores mencionaron en orden de mayor a menor incidencia, al Ministerio de Salud, LAICA que les ha ofrecido capacitaciones, MAG brinda insumos y asesoría, Coopecañera (venta de insumos), Coopevictoria (recepción de caña que no pueden vender para dulce), el Instituto de Desarrollo Rural (INDER) , Instituto Nacional de Aprendizaje (INA), Universidad de Costa Rica (UCR), (estas tres últimas como entes de capacitación y asesoría), MINAE, que regula el aspecto ambiental de manejo de desechos y Dirección de Investigación y Extensión de la Caña de Azúcar (DIECA), como capacitador.

Por su parte, la percepción que tienen los trapicheros de las instituciones y su accionar mencionan en el siguiente orden a: MS, MAG, Ministerio de Trabajo (MT) regulador en materia laboral, INS ofrece y regula pólizas de los trabajadores del trapiche, Instituto Mixto de Ayuda Social (IMAS) con algún apoyo financiero y capacitación, UCR, MINAE, Concejo Nacional de Producción (CNP).

En el caso del financiamiento, este ha sido más asequible para los trapicheros, en cuanto a los productores solamente el $4 \%$ ha obtenido acceso adecuado a algún tipo de financiamiento. 


\section{Conclusiones y recomendaciones}

Como se planteó al inicio del artículo, el presente trabajo busca determinar los principales factores y actores de la cadena de la agroindustria familiar del dulce (empleando el enfoque de CGM), que inciden en el desarrollo rural sostenible de la comunidad de La Paz, San Ramón. A la luz de este objetivo se presentan las conclusiones en dos líneas: una hacia los actores principales de la cadena y otra sobre la sostenibilidad de la cadena de valor del dulce.

\section{Actores de la cadena de dulce en La Paz}

Los productores: las personas jóvenes están poco vinculadas con la actividad cañera, lo que disminuye la posibilidad de sostenibilidad futura de la actividad. No obstante, la comunidad valora la labor de los productores y trapicheros, además ven la caña y el dulce como un distintivo de la zona.

Los productores tienen conciencia ambiental y deseos de realizar mejores prácticas agrícolas, pero no saben cómo hacerlo, debido a la carencia de información y asesoría. Tampoco tienen conocimiento de la legislación o normativa vinculante en relación con la caña. Las instituciones estatales ofrecen principalmente capacitaciones a los productores, pero siguen existiendo vacíos en apoyo principalmente el relacionado con el financiamiento accesible.

En el eslabón agrícola, sigue coexistiendo el pequeño productor cañero, el cual utiliza mano de obra familiar, tiene una producción a pequeña escala, y en algunos casos siguen utilizando técnicas tradicionales de producción y transporte como la movilización de la caña de azúcar mediante carretas de bueyes.

Los trapiches y trapicheros: el eslabón agroindustrial de la producción de panela o dulce sigue siendo una actividad importante y tradicional en la comunidad de La Paz de San Ramón. Se destaca la contracción del mercado nacional en los últimos 30 años, debido a nuevas opciones de consumo en la generaciones más jóvenes, las cuales han ido sustituyendo una bebida tradicional como el "agua dulce" por otras como café, té o gaseosas

Las posibilidades de mejora del mercado tanto a nivel nacional como internacional son factibles, a través de la producción de caña y dulce orgánicos. Esto favorece el surgimiento de nuevos mercados no tradicionales como el europeo.

Comerciante local: A pesar de la diversidad de productos que comercializan a través de la transformación del jugo de caña, no es suficiente para garantizar su estabilidad y tienen muchas necesidades dentro del negocio que no pueden satisfacer, no tienen apoyo o reconocimiento institucional. 
Vol 37, N 55, (1-13), EISSN: 2215-2997, julio - diciembre, 2017

URL: www.revistas.una.ac.cr/abra

DOI: http://dx.doi.org/10.15359/abra.37-55.3

\section{Sostenibilidad en la cadena y la agroindustria familiar del dulce}

Desde la perspectiva social, la cadena tiene un aporte local importante a través del empleo y activación de la economía. El tener autonomía productiva genera cierto grado de independencia de factores externos, y el patrón de minifundio con acceso a tierras es común para la mayor cantidad de propietarios, pero a su vez es una característica negativa, cuando de maximizar producción e incursión a mercados se trata.

El acervo de conocimiento de los actores de la cadena es amplio, debido a años de experiencia y a la historia agraria de La Paz. Sin embargo, existe el riesgo de que el relevo generacional no se dé adecuadamente y la transmisión del conocimiento se pierda debido a la poca vinculación de jóvenes en la cadena. No obstante, la zona cuenta con un alto grado de organización social, lo que facilita alcanzar objetivos comunes, donde las mujeres y jóvenes deberían de tener mayor participación.

A nivel de cadena hay una sinergia entre todos los actores y la comunidad, ambos consideran al otro agente indispensable, no solo para que la cadena funcione, sino como forma de identidad cultural. El consumidor del cantón de San Ramón tienen intención de apoyar la economía local, además de conciencia social y ambiental a la hora de comprar el duce o sus derivados.

Se destaca el uso de métodos manuales o mecánicos para remover las malezas, aunque también se utilizan insumos químicos. En el caso de los últimos se requiere de capacitación sobre su manejo, ya que se generan residuos plásticos y el destino final de muchos no es el apropiado. Un aspecto positivo es que prevalece el uso de bueyes, los cuales compactan menos los terrenos que un tractor y aportan a la preservación de la cultura rural.

En cuanto al aspecto político- institucional, esta cadena enfrenta la realidad de la agroindustria rural y la agricultura familiar de Costa Rica, carecen de políticas específicas y diferenciadas para estos sectores tan locales e idiosincráticos, con necesidades y requerimientos especiales, que en muchos casos no se pueden generalizar con los del resto del país.

Es preciso adoptar una visión global de la cadena de dulce y no sectorial. Esto como una forma de aportar a la mejora y sostenibilidad de la misma por parte de las distintas instituciones vinculadas, especialmente en tema de capacitaciones, desarrollo de mercado, acceso a tecnologías más amigables con el ambiente y financiamiento de los actores de la cadena. Sin dejar de lado la difusión por parte de las instituciones, hacia los actores de las nuevas políticas y opciones que tiene el país y que podría aportar a la mejora de la cadena; contribuyendo, así, al empoderamiento de los productores rurales y a la mejora real de sus condiciones de vida. No vista la población campesina desde una perspectiva de proletariado pobre, sino de agentes de cambio que encuentran en la agricultura una forma de vida y no un simple negocio (Hernández, et.al., 2015). 
El dulce en La Paz y su producción está medianamente bien conformada en cuanto a elementos sociales, ambientales, culturales y económicos. Por lo tanto, es una práctica de agricultura familiar con viabilidad para la sostenibilidad, con limitantes y muchas áreas de mejora, pero con el potencial para hacerlo y con aspectos positivos que la hacen meritoria de un modelo a estudiar y resaltar como agricultura familiar en Costa Rica.

\section{Referencias bibliográficas}

Castro, S. (2007-2008). Conservación del patrimonio cultural y generación de empleo: Posibilidades y riesgos. Cuadernos de Antropología, 17-18, 89-101. Recuperado de http://revistas.ucr.ac.cr/ index.php/antropologia/article/view/7225

Comité Nacional de Agricultura Familiar de Costa Rica. (2015). Agricultura familiar Costa Rica: Gestión de riesgos sanitarios. San José, C.R: Ministerio de Agricultura y Ganadería [MAG]. Recuperado de http://siatma.org/sitios/biblioteca/uploads/5._Cosata_Rica_Presentaci\%C3\%B3n_AF, Costa_Rica_3_pdf

Cordero, R., \& Valenciano-Salazar, J.(2015). Gobernanza de las empresas dominantes en la cadena del café: El caso de la región de Turrialba, Costa Rica. Revista ABRA, 35(51), 1-26. Recuperado de http://www.revistas.una.ac.cr/index.php/abra/article/view/7541

Díaz, R. y Hartwich, F. (2005). Cadenas de valor: Un paso innovador para la agricultura Centroamérica. Revista Alternativas para el Desarrollo, 96, 34-45. Recuperado de http://www.repo.funde. org/id/eprint/441

Díaz, R.y Pelupessy, W. (2004). Agricultores, consumidores y la mediación institucional en las cadenas agro-alimentarias globales en Centroamérica. Revista Centroamericana de Ciencias Sociales, 1(1), 25-56. Recuperado de http://www.flacso.or.cr/index.php/publicaciones-jb-br-jb-ilabor-editorial-jb-i/revista-de-ciencias-sociales.

Flores, J. (2007). Agrocadena de la caña de azúcar para la producción de dulce. Puriscal, CR: Ministerio de Agricultura y Ganadería (MAG), Dirección Regional Central Sur. Recuperado de http:// www.mag.go.cr/bibliotecavirtual/a00066.pdf

Gereffi, G. y Korzeniewicz, M. (Eds.). (1994). Commodity Chains and Global Capitalism. Wetport, Connecticut: PRAEGER. Recuperado de https://www.questia.com/library/2963265/ commodity-chains-and-global-capitalism 
Hernández, J., Carazo, E. y García, T. (2015). Informe de investigación: Fortalecimiento organizativo de organizaciones campesinas. C.R.: Centro de Investigación en Cultura y Desarrollo (CICDE). Universidad Estatal a Distancia. Recuperado de http://investiga.uned.ac.cr/cicde/index.php/ informes-de-investigacion/95-orgcampesinas

INEC (2011). Costa Rica: Indicadores económicos, según provincia, cantón y distrito. Recuperado de http://www.inec.go.cr/censos/censos-2011.

Kaplinsky, R. y Morris M. (2000). Handbook for value chain research. International Development Research Center [IDRC]. Recuperado de http://www.prism.uct.ac.za/Papers/VchNov01.pdf

Ministerio de Agricultura y Ganadería [MAG]. (2012). Plan sectorial de agricultura familiar 20112014. Sector Agropecuario. Equipo Técnico Sectorial de Agricultura Familiar. San José, C.R. Recuperado de http://www.mag.go.cr/bibliotecavirtual/a00303.pdf

Organización de las Naciones Unidas para la Agricultura y la Alimentación [FAO]. (2012). Marco estratégico de mediano plazo de cooperación de la FAO en agricultura familiar en América Latina y el Caribe (2012-2015) (Documento de consulta con los países miembros). FAO. Recuperado de http://www.fao.org/docrep/019/as169s/as169s.pdf

Organización de las Naciones Unidas [ONU]. (1987). Informe Brundtland (Informe sobre la Comisión Mundial sobre Medio Ambiente). Editorial Universidad de las Naciones Unidas. Recuperado de http://www.un-documents.net/ocf-02.htm\#l

Pelupessy, W. (2001). El enfoque de la cadena global de mercancías como herramienta analítica en las economías en vías de desarrollo. Revista Economía y Sociedad, 6(15), 111-120. Recuperado de http://www.revistas.una.ac.cr

Samper, M., Masis, G., Miranda, O., Díaz, O., Martín, P., González, H. ... Arce, J. (2006). Jornada de reflexión y debate: Políticas agropecuarias, estrategias de desarrollo rural, seguridad alimentaria, pobreza rural y servicios de extensión agrícola. San José, CR: IICA, UCR, UNA, PDR-MAG, ANEAF, FAO, UNED, ITCR. Recuperado de http://repiica.iica.int/docs/B0386e/ B0386e.pdf

Schneider, S. (2003). Teoría social, agricultura familiar e pluriactividade. Revista Brasileira de Ciências Sociais, 18 (51), 99-192. doi:10.1590/S0102-69092003000100008

Secretaría Ejecutiva de Planificación Sectorial Agropecuaria. [SEPSA]. (2012). Boletín estadístico agropecuario № 22. San José, C.R: SEPSA. Recuperado de http://www.sepsa.go.cr/DOCS/ BEA/BEA22.pdf 
Sepúlveda, S. (2008). Gestión del desarrollo sostenible en territorios rurales: Métodos para la planificación. San José, C.R.: Instituto Interamericano de Cooperación para la Agricultura [IICA]. Recuperado de http://repiica.iica.int/docs/B0712E/B0712E.pdf

Sepúlveda, S., Rodríguez, A., Echeverri, R., y Portilla, M. (2003). El enfoque territorial de desarrollo rural. San José, C.R.: Instituto Interamericano de Cooperación para la Agricultura [IICA]. Recuperado de http://repiica.iica.int/docs/B0400e/B0400e.pdf

Soto, M., León, J. y Arroyo, N. (2010). Desarrollo histórico del sector agroindustrial de la caña de azúcar en el siglo XX: Aspectos económicos, institucionales y tecnológicos (Informe para discusión). San José, C.R: Instituto de Investigaciones de Ciencias Económicas [IICE], Universidad de Costa Rica. Recuperado de http://www.iice.ucr.ac.cr/Informe\%20Ca\%C3\%B1a\%20_Doc\%20 de\%20trabajo_.pdf 
Anexos

Anexo 1.Guía de variables y atributos para el productor de la cadena del dulce

\begin{tabular}{|c|c|c|c|}
\hline \multicolumn{4}{|c|}{ Actor de la Cadena: PRODUCTOR } \\
\hline Dimensiones & Aspectos a analizar & $\begin{array}{l}\text { Guía de variables según } \\
\text { ítems en encuesta }\end{array}$ & $\begin{array}{l}\text { Guía de atributos según ítems en } \\
\text { encuesta }\end{array}$ \\
\hline \multirow{5}{*}{$\begin{array}{l}\text { I- Insumo- } \\
\text { producto (valor } \\
\text { agregado-VA) }\end{array}$} & $\begin{array}{l}\text { Información General } \\
\text { Materias primas }\end{array}$ & $\begin{array}{l}\text { 1.1 Edad, miembros hogar, } \\
2.3 \text { hectáreas cultivadas, } \\
2.6 \text { años de experiencia, } \\
2.8 \text { cantidad y costo de } \\
\text { insumos. }\end{array}$ & $\begin{array}{l}\text { 1.1 Escolaridad, ocupación, } 1.2 \text { tipo } \\
\text { organización, } 2.1 \text { fuente de semillas, } \\
2.2 \text { tipo semilla, } 2.4 \text { tipo propiedad, } .2 .5 \\
\text { tipo actividades, } 2.7 \text { actividades para la } \\
\text { preparar terreno, } 2.9 \text { uso orgánico, } \\
2.10 \text { tipo maquinaria. }\end{array}$ \\
\hline & Producción & $\begin{array}{l}2.12 \text { Horas de trabajo, } 2.14 \\
\text { cantidad de meses de } \\
\text { contrato, } 2.15 \text { cantidad } \\
\text { personal fijo/temporal, } 2.16 \\
\text { salario mensual. }\end{array}$ & $\begin{array}{l}2.11 \text { Fases de cultivo, } 2.12 \text { género de } \\
\text { empleados, trabajo familiar. } 2.13 \text { tipo } \\
\text { trabajador, } 2.17 \text { tipo maquinaria, } 2.18 \\
\text { calidad de maquinaria. } 2.19 \text { actividades } \\
\text { de mantenimiento, } 2.20 \text { control } \\
\text { biológico, } 2.21 \text { quema de cañal, } 2.22 \\
\text { obtención de agua, } 2.24 \text { destino de } \\
\text { residuos, } 2.25 \text { problema/fortaleza, } \\
2.26 \text { necesidad. }\end{array}$ \\
\hline & Procesamiento & & \\
\hline & Comercialización & $\begin{array}{l}\text { 2.27 Toneladas } \\
\text { mensuales, } 2.28 \text { ingreso } \\
\text { semanal }\end{array}$ & $\begin{array}{l}2.27 \text { Trapiche de entrega, } 2.9 \text { dificultad } \\
\text { entrega. }\end{array}$ \\
\hline & $\begin{array}{l}\text { Consumo final y valor } \\
\text { agregado }\end{array}$ & & \\
\hline \multirow[t]{2}{*}{$\begin{array}{l}\text { Il-Geográfica } \\
\text { (ubicación) }\end{array}$} & Caracterización de territorio & $\begin{array}{l}\text { 3.1 Calificación clima/suelo, } \\
3.3 \text { hectáreas bosque, } 3.6 \\
\% \text { de ingresos mensuales }\end{array}$ & $\begin{array}{l}\text { 3.2 Tipo topografía, } 3.3 \text { cobertura } \\
\text { boscosa, } 3.4 \text { disponibilidad de agua, } \\
3.5 \text { actividades productivas, } 3.6 \\
\text { actividades económicas hogar. }\end{array}$ \\
\hline & $\begin{array}{l}\text { Producción de caña de la } \\
\text { zona }\end{array}$ & 3.10 Costo de flete. & $\begin{array}{l}\text { 3.7 Medio transporte, } 3.8 \text { transporte } \\
\text { ideal, } 3.9 \text { tipo transporte, } 3.11 \text { variedad } \\
\text { de caña. }\end{array}$ \\
\hline $\begin{array}{l}\text { Ill- Fuerza } \\
\text { motriz } \\
\text { (estructura de } \\
\text { control) }\end{array}$ & $\begin{array}{l}\text { Influencia de actores en la } \\
\text { cadena }\end{array}$ & & $\begin{array}{l}4.1 \text { actores de la cadena, } 4.2 \text { actores } \\
\text { principales de la cadena, } 4.3 \text { mejoras } \\
\text { en producción, } 4.4 \text { motivo entrega, } 4.5 \\
\text { limitantes para entregar, } 4.6 \text { tipo de } \\
\text { intercambio }\end{array}$ \\
\hline \multirow{2}{*}{$\begin{array}{l}\text { IV- } \\
\text { Institucionales } \\
\text { (políticas } \\
\text { estatales) }\end{array}$} & Regulaciones & & $\begin{array}{l}\text { 5.1 Conoce legislación, } 5.2 \text { tipo } \\
\text { legislación, } 5.3 \text { aplicabilidad de leyes, } \\
5.4 \text { opinión de leyes, } 5.5 \text { dificultad } \\
\text { ambiental }\end{array}$ \\
\hline & Instituciones presentes & & $\begin{array}{l}5.6 \text { Instituciones presentes. } 5.7 \text { tipo de } \\
\text { apoyo, } 5.8 \text { proyectos gubernamentales, } \\
5.9 \text { participación en programas, } 5.10 \\
\text { recursos para inversión. } 5.11 \text { acceso al } \\
\text { crédito, } 5.12 \text { fuentes de crédito. }\end{array}$ \\
\hline $\begin{array}{l}\text { Información } \\
\text { adicional }\end{array}$ & Prácticas/turismo/asesoría & & $\begin{array}{l}6.1 \text { prácticas culturales, } \\
6.2 \text { diversificación, } 6.3 \text { Turismo, } 6.4 \\
\text { participación turismo, } 6.5 \text { capacitación }\end{array}$ \\
\hline
\end{tabular}

Fuente: elaboración propia. 
Anexo 2. Guía de variables y atributos para el encargado de trapiche de la cadena del dulce

\begin{tabular}{|c|c|c|c|}
\hline \multicolumn{4}{|c|}{ Actor de la Cadena: ENCRAGADO DE TRAPICHE ( TRAPICHERO) } \\
\hline Dimensiones & Aspectos a analizar & $\begin{array}{l}\text { Guía de variables } \\
\text { según ítems en } \\
\text { encuesta }\end{array}$ & $\begin{array}{l}\text { Guía de atributos según ítems en } \\
\text { encuesta }\end{array}$ \\
\hline \multirow{5}{*}{$\begin{array}{l}\text { I- Insumo- } \\
\text { producto } \\
\text { (valor } \\
\text { agregado-VA-) }\end{array}$} & $\begin{array}{l}\text { Información general } \\
\text { Materias primas }\end{array}$ & $\begin{array}{l}1.1 \text { Edad, miembros de } \\
\text { hogar } 1.3 \text { años de } \\
\text { experiencia, } 1.6 \text { años de } \\
\text { funcionamiento. }\end{array}$ & $\begin{array}{l}\text { 1.1 Escolaridad, ocupación, } 1.2 \text { nombre } \\
\text { trapiche, } 1.4 \text { tipo tecnologia. } 1.5 \\
\text { pertenencia del trapiche, } 1.7 \text { cambio de } \\
\text { tecnología, } 1.8 \text { satisfacción tecnológica, } \\
2.1 \text { obtención de caña, } 2.2 \text { variedades de } \\
\text { caña, } 2.3 \text { material de combustión, } 2.4 \\
\text { obtención de agua. }\end{array}$ \\
\hline & Producción & $\begin{array}{l}\text { 2.6 Cantidad días } \\
\text { operación, horas } \\
\text { diarias, horas } \\
\text { semanales, } 2.8 \text { cantidad } \\
\text { personal fijo/temporal, } \\
2,9 \text { toneladas } \\
\text { diarias/semanales, } 2.10 \\
\text { cantidad caña propia. }\end{array}$ & $\begin{array}{l}2.5 \text {, Calidad cantidad de agua, } 2.7 \text { tipo } \\
\text { trabajador } 2.8 \text { género de empleados. }\end{array}$ \\
\hline & Procesamiento & $\begin{array}{l}2.15 \text { cantidad de dulce, } \\
\% \text { de ventas. }\end{array}$ & $\begin{array}{l}2.111 \text { Actividades productivas, } 2.2 \\
\text { manejo residuos, } 2.13 \text { mejora manejo } \\
\text { residuos, } 2.14 \text { productos orgánicos, } 2.15 \\
\text { presentación dulce, } 2.16 \text { necesidad, }\end{array}$ \\
\hline & Comercialización & & $\begin{array}{l}2.17 \text { condición de la demanda, } 2.18 \\
\text { variación en demanda, } 2.19 \text { mercado del } \\
\text { dulce, } 2.20 \text { comercialización de } \\
\text { productos, } 2.21 \text { principales compradores, } \\
2.22 \text { dificultades. }\end{array}$ \\
\hline & Consumo final y VA & & \\
\hline \multirow{2}{*}{$\begin{array}{l}\text { Il-Geográfica } \\
\text { (ubicación) }\end{array}$} & $\begin{array}{l}\text { Caracterización de } \\
\text { territorio }\end{array}$ & & \\
\hline & $\begin{array}{l}\text { Ventajas comparativas } \\
\text { que permiten la } \\
\text { producción de caña de la } \\
\text { zona }\end{array}$ & & $\begin{array}{l}\text { 3.1 Aumento/disminución oferta caña, } 3.2 \\
\text { aumento/disminución demanda caña, } 3.3 \\
\text { tipo de variedades de caña, } 3.4 \\
\text { aceptación de variedades, } 3.5 \text { calidad y } \\
\text { rendimiento de caña. }\end{array}$ \\
\hline $\begin{array}{l}\text { III- Fuerza } \\
\text { motriz } \\
\text { (estructura } \\
\text { control) }\end{array}$ & $\begin{array}{l}\text { Influencia de actores en } \\
\text { cadena }\end{array}$ & & $\begin{array}{l}\text { 4.1 Actores de la cadena, } 4.2 \text { actores } \\
\text { principales de la cadena, } 4.3 \\
\text { dependencia de marcado, } 4.4 \text { mejoras en } \\
\text { producción, } 4.5 \text { tipo de intercambio. }\end{array}$ \\
\hline \multirow{2}{*}{$\begin{array}{l}\text { IV- } \\
\text { Institucionales } \\
\text { (políticas } \\
\text { estatales) }\end{array}$} & Regulaciones & & $\begin{array}{l}\text { 5.1 Conoce legislación, } 5.2 \text { tipo } \\
\text { legislación, } 5.3 \text { aplicabilidad de leyes, } 5.4 \\
\text { opinión de leyes, } 5.5 \text { dificultad ambiental. }\end{array}$ \\
\hline & Instituciones presentes & & $\begin{array}{l}5.6 \text { Instituciones presentes. } 5.7 \text { tipo de } \\
\text { apoyo, } 5.8 \text { proyectos gubernamentales, } \\
5.9 \text { detalle del proyecto, } 5.10 \\
\text { participación en programas, } 5.11 \\
\text { recursos para inversión. } 5.12 \text { acceso al } \\
\text { crédito, } 5.13 \text { fuentes de crédito. }\end{array}$ \\
\hline $\begin{array}{l}\text { Información } \\
\text { adicional }\end{array}$ & Prácticas/turismo/asesoría & & $\begin{array}{l}6.1 \text { prácticas culturales, } \\
6.2 \text { diversificación, } 6.3 \text { Turismo, } 6.4 \\
\text { participación turismo, } 6.5 \text { capacitación }\end{array}$ \\
\hline
\end{tabular}

Fuente: elaboración propia. 
Anexo 3. Guía de variables y atributos para el comerciante local de la cadena del dulce

\begin{tabular}{|c|c|c|c|}
\hline \multicolumn{4}{|c|}{ Actor de la Cadena: COMERCIANTE DEL DULCE } \\
\hline Dimensiones & Aspectos a analizar & $\begin{array}{l}\text { Guía de variables } \\
\text { según ítems en } \\
\text { encuesta }\end{array}$ & $\begin{array}{l}\text { Guía de atributos según ítems en } \\
\text { encuesta }\end{array}$ \\
\hline \multirow{5}{*}{$\begin{array}{l}\text { I- Insumo- } \\
\text { producto } \\
\text { (valor } \\
\text { agregado-va-) }\end{array}$} & $\begin{array}{l}\text { Información general } \\
\text { Materias primas }\end{array}$ & $\begin{array}{l}1.1 \text { Edad, miembros de } \\
\text { hogar, } 1.3 \text { años de } \\
\text { trabajo }\end{array}$ & $\begin{array}{l}\text { 1.1 Escolaridad, ocupación, } 1.2 \\
\text { pertenencia del negocio, } 1.3 \text { otras } \\
\text { actividades. }\end{array}$ \\
\hline & Producción & & \\
\hline & Procesamiento & & \\
\hline & Comercialización & $\begin{array}{l}\text { 2.2 Cantidad de dulce, } \\
2.5 \text { salario hora/mes, } 2.7 \\
\text { ingreso semanal, } 2.8 \\
\text { costo de transporte. }\end{array}$ & $\begin{array}{l}\text { 2.1 Actividades realizadas, } 2.2 \text { origen } \\
\text { de compra, frecuencia, } 2.3 \text { trabajo } \\
\text { familiar, } 2.4 \text { tipo de trabajador, } 2.6 \\
\text { procesos adicionales, } 2.9 \\
\text { problema/fortaleza, } 2.10 \text { necesidad, } \\
2.11 \text { dificultad, } 2.12 \text { comercialización } \\
\text { productos, } 2.13 \text { mercado del dulce, } \\
2.14 \text {, aumento/disminución oferta } \\
\text { dulce, } \\
2.15 \text { aumento/disminución demanda } \\
\text { dulce, } 2.16 \text { quejas del producto, } 2.17 \\
\text { frecuencia de quejas. }\end{array}$ \\
\hline & Consumo final y VA & & \\
\hline \multirow{2}{*}{$\begin{array}{l}\text { II-Geográfica } \\
\text { (ubicación) }\end{array}$} & $\begin{array}{l}\text { Caracterización de } \\
\text { territorio }\end{array}$ & $\begin{array}{l}3.3 \% \text { de ingresos } \\
\text { mensuales }\end{array}$ & $\begin{array}{l}\text { 3.1 Proyección de imagen de dulce } \\
\text { comunal. } 3.2 \text { actividades adicionales, } \\
3.3 \text { actividades económicas. }\end{array}$ \\
\hline & $\begin{array}{l}\text { Ventajas comparativas } \\
\text { que permiten la } \\
\text { producción de caña de la } \\
\text { zona }\end{array}$ & & \\
\hline $\begin{array}{l}\text { III- Fuerza } \\
\text { motriz } \\
\text { (estructura de } \\
\text { control) }\end{array}$ & $\begin{array}{l}\text { Influencia de actores en la } \\
\text { cadena }\end{array}$ & & $\begin{array}{l}\text { 4.1 Razones de compra de dulce, } 4.2 \\
\text { actor principal, } 4.3 \text { mejoras, } 4.4 \\
\text { actores principales, } 4.5 \text { tipo de } \\
\text { intercambio. }\end{array}$ \\
\hline \multirow{2}{*}{$\begin{array}{l}\text { IV- } \\
\text { Institucionales } \\
\text { (políticas } \\
\text { estatales) }\end{array}$} & Regulaciones & & $\begin{array}{l}\text { 5.1 Conoce legislación, } 5.2 \text { tipo } \\
\text { legislación, } 5.3 \text { aplicabilidad de } \\
\text { leyes, } 5.4 \text { opinión de leyes, } 5.5 \\
\text { dificultad comercial. }\end{array}$ \\
\hline & Instituciones presentes & & $\begin{array}{l}5.6 \text { Instituciones presentes. } 5.7 \\
\text { apoyo institucional, } 5.8 \text { tipo de apoyo } \\
5.9 \text { proyectos gubernamentales, } 5.10 \\
\text { participación en programas, } 5.11 \\
\text { recursos para inversión. } 5.12 \text { acceso } \\
\text { al crédito, } 5.13 \text { fuentes de crédito. }\end{array}$ \\
\hline $\begin{array}{l}\text { Información } \\
\text { adicional }\end{array}$ & Prácticas/turismo/asesoría & & $\begin{array}{l}6.1 \text { percepción compradores, } \\
6.2 \text { diversificación, } 6.3 \text { capacitación }\end{array}$ \\
\hline
\end{tabular}

Fuente: Elaboración propia. 
Anexo 4. Guía de variables y atributos para el consumidor de la cadena del dulce

Actor de la Cadena: CONSUMIDOR

\begin{tabular}{|c|c|c|c|}
\hline Dimensiones & Aspectos a analizar & $\begin{array}{l}\text { Guía de variables según } \\
\text { ítems en encuesta }\end{array}$ & $\begin{array}{c}\text { Guía de atributos según ítems } \\
\text { en encuesta }\end{array}$ \\
\hline \multirow{5}{*}{$\begin{array}{l}\text { I- Insumo- } \\
\text { producto } \\
\text { (valor } \\
\text { agregado-VA-) }\end{array}$} & $\begin{array}{l}\text { Información General } \\
\text { Materias primas }\end{array}$ & $\begin{array}{l}\text { 1.1 Edad, } 2.3 \text { hectáreas } \\
\text { cultivadas, } 2.6 \text { años de } \\
\text { experiencia, } 2.8 \text { cantidad y } \\
\text { costo de insumos. }\end{array}$ & $\begin{array}{l}\text { 1.1 Escolaridad, ocupación, } \\
\text { miembros hogar, } 1.2 \text { tipo } \\
\text { organización, } 2.1 \text { fuente de } \\
\text { semillas, } 2.2 \text { tipo semilla, } 2.4 \text { tipo } \\
\text { propiedad, } .2 .5 \text { tipo actividades, } \\
2.7 \text { actividades para la siembra, } \\
2.9 \text { uso orgánico, } 2.10 \text { tipo } \\
\text { maquinaria. }\end{array}$ \\
\hline & Producción & $\begin{array}{l}2.12 \text { Horas de trabajo, } 2.14 \\
\text { cantidad de meses de } \\
\text { contrato, } 2.15 \text { cantidad } \\
\text { personal fijo/temporal, } 2.16 \\
\text { salario, }\end{array}$ & $\begin{array}{l}2.11 \text { Fases de cultivo, } 2.12 \text { género } \\
\text { de empleados. } 2.13 \text { tipo trabajador, } \\
2.17 \text { tipo maquinaria, } 2.18 \text { calidad } \\
\text { de maquinaria. } 2.19 \text { actividades de } \\
\text { mantenimiento, } 2.20 \text { control } \\
\text { biológico, } 2.21 \text { quema de cañal, } \\
2.22 \text { origen de agua, } 2.23 \text { destino } \\
\text { de residuos, } 2.24 \\
\text { problema/fortaleza, } 2.25 \\
\text { necesidad. }\end{array}$ \\
\hline & Procesamiento & & \\
\hline & Comercialización & $\begin{array}{l}\text { 2.26 Toneladas } \\
\text { mensuales, } 2.27 \text { ingreso } \\
\text { semanal }\end{array}$ & $\begin{array}{l}2.26 \text { Nombre trapiche, } 2.28 \\
\text { dificultad entrega. }\end{array}$ \\
\hline & $\begin{array}{l}\text { Consumo final y valor } \\
\text { agregado }\end{array}$ & & \\
\hline \multirow{2}{*}{$\begin{array}{l}\text { Il-Geográfica } \\
\text { (ubicación) }\end{array}$} & $\begin{array}{l}\text { Caracterización de } \\
\text { territorio }\end{array}$ & $\begin{array}{l}\text { 3.1 Calificación clima/suelo, } \\
\text { 3.3 hectáreas bosque, }\end{array}$ & $\begin{array}{l}\text { 3.2 Tipo topografía, } 3.3 \text { área } \\
\text { boscosa, } 3.4 \text { disponibilidad de } \\
\text { agua, } 3.5 \text { actividades productivas. }\end{array}$ \\
\hline & $\begin{array}{l}\text { Producción de caña } \\
\text { de la zona }\end{array}$ & 3.9 Costo de flete. & $\begin{array}{l}\text { 3.6 Medio transporte, } 3.7 \\
\text { transporte ideal, } 3.8 \text { tipo } \\
\text { transporte, } 3.10 \text { variedad de caña. }\end{array}$ \\
\hline $\begin{array}{l}\text { III- Fuerza } \\
\text { motriz } \\
\text { (estructura de } \\
\text { control) }\end{array}$ & $\begin{array}{l}\text { Influencia de actores } \\
\text { en la cadena }\end{array}$ & & $\begin{array}{l}4.1 \text { actores de la cadena, } 4.2 \\
\text { actores principales de la cadena, } \\
4.3 \text { mejoras en producción, } 4.4 \\
\text { motivo entrega, } 4.6 \text { limitantes para } \\
\text { entregar, } 4.7 \text { tipo de intercambio }\end{array}$ \\
\hline \multirow{2}{*}{$\begin{array}{l}\text { IV- } \\
\text { Institucionales } \\
\text { (políticas } \\
\text { estatales) }\end{array}$} & Regulaciones & & $\begin{array}{l}\text { 5.1 Conoce legislación, } 5.2 \text { tipo } \\
\text { legislación, } 5.3 \text { aplicabilidad de } \\
\text { leyes, } 5.4 \text { opinión de leyes, } 5.5 \\
\text { dificultad ambiental }\end{array}$ \\
\hline & $\begin{array}{l}\text { Instituciones } \\
\text { presentes }\end{array}$ & & $\begin{array}{l}5.6 \text { Instituciones presentes. } 5.7 \text { tipo } \\
\text { de apoyo, } 5.8 \text { proyectos } \\
\text { gubernamentales, } 5.9 \text { participación } \\
\text { en programas, } 5.10 \text { recursos para } \\
\text { inversión. } 5.11 \text { acceso al crédito, } \\
5.12 \text { fuentes de crédito. }\end{array}$ \\
\hline
\end{tabular}

Fuente: elaboración propia. 